\title{
Antibody-dependent infection of human macrophages by severe acute respiratory syndrome coronavirus
}

Ming Shum Yip ${ }^{1+}$, Nancy Hiu Lan Leung ${ }^{1 \dagger}$, Chung Yan Cheung ${ }^{2}$, Ping Hung Li ${ }^{1}$, Horace Hok Yeung Lee ${ }^{1}$, Marc Daëron ${ }^{3,4}$, Joseph Sriyal Malik Peiris ${ }^{1}$, Roberto Bruzzone ${ }^{1,5^{*}}$ and Martial Jaume ${ }^{1 *}$

\begin{abstract}
Background: Public health risks associated to infection by human coronaviruses remain considerable and vaccination is a key option for preventing the resurgence of severe acute respiratory syndrome coronavirus (SARS-CoV). We have previously reported that antibodies elicited by a SARS-CoV vaccine candidate based on recombinant, full-length SARS-CoV Spike-protein trimers, trigger infection of immune cell lines. These observations prompted us to investigate the molecular mechanisms and responses to antibody-mediated infection in human macrophages.
\end{abstract}

Methods: We have used primary human immune cells to evaluate their susceptibility to infection by SARS-CoV in the presence of anti-Spike antibodies. Fluorescence microscopy and real-time quantitative reverse transcriptase polymerase chain reaction (RT-PCR) were utilized to assess occurrence and consequences of infection. To gain insight into the underlying molecular mechanism, we performed mutational analysis with a series of truncated and chimeric constructs of fragment crystallizable $\gamma$ receptors ( $F(\gamma R)$, which bind antibody-coated pathogens.

Results: We show here that anti-Spike immune serum increased infection of human monocyte-derived macrophages by replication-competent SARS-CoV as well as Spike-pseudotyped lentiviral particles (SARS-CoVpp). Macrophages infected with SARS-CoV, however, did not support productive replication of the virus. Purified anti-viral IgGs, but not other soluble factor(s) from heat-inactivated mouse immune serum, were sufficient to enhance infection. Antibody-mediated infection was dependent on signaling-competent members of the human FcyRll family, which were shown to confer susceptibility to otherwise naïve ST486 cells, as binding of immune complexes to cell surface FcyRll was necessary but not sufficient to trigger antibody-dependent enhancement (ADE) of infection. Furthermore, only FcyRll with intact cytoplasmic signaling domains were competent to sustain ADE of SARS-CoVpp infection, thus providing additional information on the role of downstream signaling by FcyRll.

Conclusions: These results demonstrate that human macrophages can be infected by SARS-CoV as a result of IgG-mediated ADE and indicate that this infection route requires signaling pathways activated downstream of binding to FcyRll receptors.

Keywords: SARS-CoV, Spike, Antibody-dependent enhancement, Macrophage, Fcy receptor, Antibodies, Pseudotypes

\footnotetext{
*Correspondence: bruzzone@hku.hk; breizh@hku.hk

${ }^{\dagger}$ Equal contributors

${ }^{1}$ HKU-Pasteur Research Pole and Center of Influenza Research, School of

Public Health, LKS Faculty of Medicine, The University of Hong Kong,

Hong Kong, Hong Kong SAR

${ }^{5}$ Department of Cell Biology and Infection, Institut Pasteur, Paris, France

Full list of author information is available at the end of the article
}

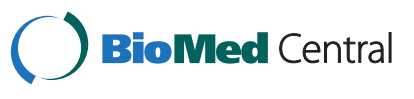

(C) 2014 Yip et al.; licensee BioMed Central Ltd. This is an Open Access article distributed under the terms of the Creative Commons Attribution License (http://creativecommons.org/licenses/by/2.0), which permits unrestricted use, distribution, and reproduction in any medium, provided the original work is properly credited. The Creative Commons Public Domain Dedication waiver (http://creativecommons.org/publicdomain/zero/1.0/) applies to the data made available in this article, unless otherwise stated. 


\section{Background}

The continuous threat of respiratory viruses to public health was exemplified by the global impact of the SARSCoV outbreak in 2003 [1], by the occurrence since 2003 of confirmed human cases of H5N1 avian influenza in many countries, particularly across Asia [2], and the 2009 H1N1 influenza pandemic [3]. The recent emergence in the Arab peninsula of a novel coronavirus responsible for the Middle East respiratory syndrome (MERS-CoV), $[4,5]$ and the new H7N9 strain of avian influenza that has jumped into humans [6,7] in China underscore the need to continue work in this direction.

It is now agreed that SARS-CoV can infect not only the respiratory tract, but can also affect other organ systems and several reports have demonstrated infection of hematopoietic cells [8-10]; however, the mechanism by which SARS-CoV enters into immune cells, which do not express the SARS-CoV receptor angiotensin-converting enzyme 2 (ACE2) [11,12] has remained poorly understood. Both C-type lectin receptors such as liver/lymph node-specific intercellular adhesion molecule-3-grabbing integrin (L-SIGN) or dendritic cell specific intercellular adhesion molecule 3-grabbing non-integrin (DC-SIGN) $[13,14]$, as well as antibody-mediated infection may provide SARS-CoV with an opportunity to modify its tropism.

Because of the lack of effective antiviral strategies to control coronaviruses infections, vaccination is still regarded as a major option for preventing resurgence of SARS and related diseases. We previously showed that a SARS-CoV vaccine candidate based on recombinant, full-length SARS-CoV Spike-protein trimers triggered infection of human B cell lines despite eliciting in vivo a neutralizing and protective immune response in rodents [15]. More recently, we demonstrated that anti-Spike antibody potentiates infection of both monocytic and lymphoid immune cell lines, not only by SARS-CoVpp but also by replication-competent SARS-coronavirus [16], thus providing evidence for a novel and versatile mechanism by which SARS-CoV can enter into target cells that do not express the conventional ACE2 virus receptor and are otherwise refractory to the virus. Such infection pathway may have implications for understanding the tropism and pathogenesis of the virus and, therefore, we further investigated the molecular and cellular mechanisms underlying ADE of SARS-CoV infection.

By monitoring the susceptibility of human bulk primary immune cells (i.e. peripheral blood mononuclear cells) we have established the occurrence of ADE of SARS-CoVpp infection in different circulating immune cell types, among which the monocytic lineage $\left(\mathrm{CD}^{+} 8^{+}\right.$cells) was the primary target. In addition to monocytes, human macrophages were also infected by SARS-CoV in presence of anti-Spike antibodies only. ADE-mediated infection of macrophages, however, did not support productive replication of the virus. Finally, we have provided evidence that the intracellular signaling motif - but not the IgG binding motif - of the Fc $\gamma \mathrm{R}$ is the key molecular determinant for triggering ADE of SARS-CoVpp. Our findings conclusively demonstrate that anti-spike serum promotes internalization of SARS-CoV by human macrophages.

\section{Results}

Primary human macrophages are susceptible to SARS-CoV infection through antibody-mediated pathway

Because our previous observations revealed that a human monocytic cell line THP-1 was susceptible to ADE of infection [16], we investigated the occurrence of ADE of infection in primary human macrophages in vitro, firstly by taking advantage of SARS-CoVpp that can be safely used to mimic the viral entry process $[15,17]$. We found that SARS-CoVpp opsonized with a 1:1000 dilution of anti-Spike serum readily infected over $80 \%$ of primary human macrophages, as determined by immunofluorescence staining of firefly luciferase at 72 hours post infection (h.p.i.). By contrast, cells exposed to SARS-CoVpp opsonized with control serum did not show any positive staining of the luciferase reporter protein (Figure 1). These experiments extend our previous observations and indicate that anti-Spike antibodies facilitate infection of SARSCoVpp into human macrophages. We next tested whether this altered tropism was also displayed by replicationcompetent SARS-CoV. Human macrophages were infected at a multiplicity of infection (MOI) of 1 with the same dilutions of anti-Spike or control immune serum and the infection pattern was examined by both immunofluorescence staining of SARS-CoV nucleocapsid protein and real-time quantitative PCR measurement of viral RNAs. Positive immunofluorescence signals were detected only at 6 h.p.i. when SARS-CoV was opsonized with both control and anti-Spike serum (Figure 2). Interestingly, whereas presence of control serum led to only modest infection by SARS-CoV ( $\sim 5 \%$ of cells), a 4 -fold increase in the percentage of positive cells was noted in the presence of anti-Spike serum for two out of three donors (Figure 2). Such enhanced infection pattern was paralleled by the number of viral gene copies measured (Figure 3). Thus, compared to inoculums containing control serum, there was a 2 to 3 -fold increase in the detection of both positive and negative strands of viral genes in macrophages infected in presence of anti-Spike serum, which was more pronounced at 1 and 6 h.p.i. There was a rapid decline in viral RNA from 6 to 24 h.p.i. for both conditions and no further changes were detected at later time points (Figure 3). However, it should be noted that the primer set used for the nucleocapsid gene could also detect the negative strand of the viral genomic RNA and could not distinguish it from sub-genomic material. In addition, 


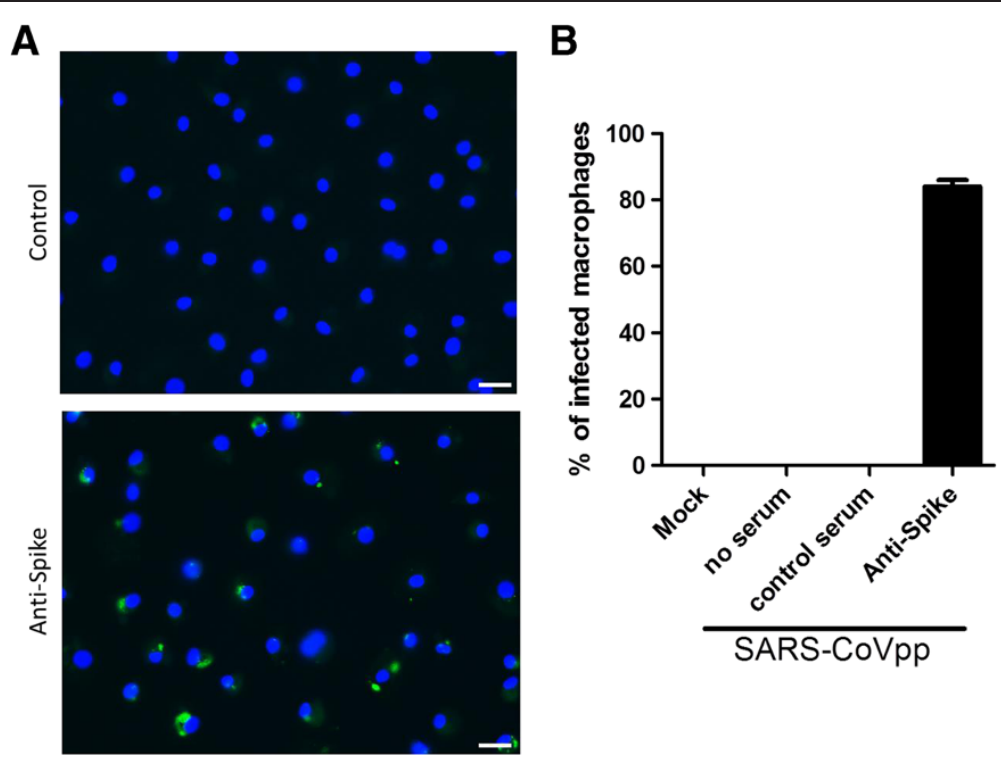

Figure 1 Anti-Spike but not control serum triggered infection of human macrophages by SARS-CoVpp. (A) Monocyte-derived macrophages were incubated for 1 hour with SARS-CoVpp carrying a luciferase reporter gene in the presence of a 1:1000 dilution of either anti-Spike or control serum and infected cells were detected by fluorescence staining of firefly luciferase (green), as described under Materials and methods. Cell nuclei were labeled with DAPI (blue). SARS-CoVpp infection of macrophages occurred only in the presence of anti-Spike serum. Images are representatives of five independent experiments using macrophages from five donors. (B) Infection was quantified by counting the percentage of immunofluorescence-positive cells in randomly chosen fields using Metamorph software. Results are shown as means \pm SEM. Scale bar: $20 \mu \mathrm{m}$.

we measured by real-time quantitative PCR copies of both viral nucleocapsid and ORF1b genes in culture supernatants to determine the release of SARS-CoV particles from the infected macrophages. Copy numbers of both viral RNAs, however, remained unchanged at all the selected time points during the course of the experiment (less than 200 copies $/ \mu \mathrm{l}$ ), regardless of whether macrophages had been infected in the presence of either control or anti-Spike serum (data not shown).

\section{ADE of SARS-CoVpp infection is dependent on the dose of IgG fraction of heat-inactivated immune-serum}

We have previously demonstrated that mouse antiSpike serum could trigger infection of Raji cells [16]. In the context of ADE, antibodies against viral proteins are considered as the major players of enhancement $[18,19]$; see for review [20,21]. To eliminate the possibility of the participation of other soluble factors during ADE of SARS, in this section we investigated the capability of anti-Spike antibodies alone in enhancing infection of immune cells. We purified IgG by protein G-sepharose chromatography from mouse anti-Spike and control serum, and used 2fold serial dilutions from 10 to $0.125 \mu \mathrm{g} / \mathrm{mL}$ of the purified portion to form immune complex with SARS-CoVpp and then infected Raji cells. Our results show that purified IgG from mouse anti-Spike serum triggered infection in Raji cells, which was more pronounced with increasing immunoglobulin concentrations (Figure 4). The flow-through (FT) from the same serum, which was diluted by the appropriate factor to be comparable to the final IgG concentration used, elicited no detectable infection at all concentrations (data not shown). Significant differences between $\mathrm{ADE}$ of infection with purified mouse anti-Spike IgG and flow-through were observed at concentrations 10 and $2.5 \mu \mathrm{g} / \mathrm{mL}$, and marginal difference was observed at $0.625 \mu \mathrm{g} / \mathrm{mL}$. As expected, neither purified IgG (Figure 4) nor flow-through from mouse control serum triggered significant ADE of infection at all concentrations.

\section{Molecular determinants of FcyRII underlying ADE of SARS-CoVpp}

Our recent work had revealed the predominant role of human FcyRII (CD32) in mediating ADE of SARS-CoV [16]. To gain further insight into the underlying molecular mechanism we have investigated the involvement of different domains of FcyRII in mediating ADE. To this end we produced a series of truncated constructs that only carried ectodomain and transmembrane domains of Fc $\gamma$ RII, and chimeric constructs with the ectodomain of one receptor and transmembrane and endodomain of another (Figure 5A). We then verified the expression of these constructs on ST486 cells by flow cytometry using a specific monoclonal antibody (clone FLI8.26) that binds to the second Ig-like domain D2 $\gamma$ of FcyRII. Of note, the Fc binding portion of the FcyRII group is very similar among Fc $\gamma$ RIIA-H131, Fc $\gamma$ RIIA-R131, Fc $\gamma$ RIIB1 [22] and also FcyRIIB2, as it harbors identical extracellular 
A
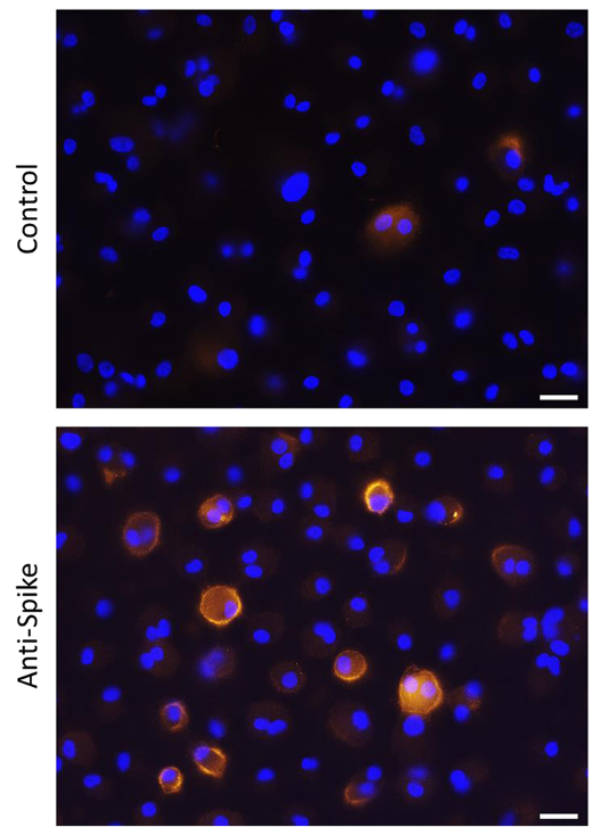

B

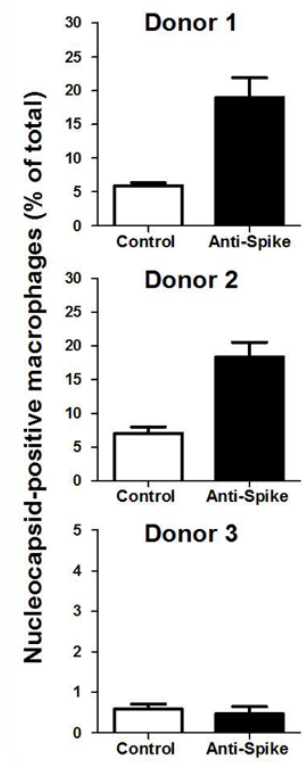

Figure 2 Anti-Spike serum enhanced SARS-CoV infection in human monocyte-derived macrophages. (A) Monocyte-derived macrophages were infected with SARS-CoV (strain HK39849) at an MOI of 1 in the presence of a 1:1000 dilution of either anti-Spike (black bars) or control (white bars) serum for 1 hour and then cultured with fresh medium for 6 hours as described under Materials and methods. After fixation, cells were permeabilized for intracellular staining of SARS-CoV nucleocapsid protein, which was revealed by TRITC-conjugated goat anti-mouse antibody (orange) while cell nuclei were stained with DAPI (blue). Images shown are representatives of the results obtained with macrophages from three donors at 6 hours post infection. Scale bar: $20 \mu \mathrm{m}$. (B) Infectivity of SARS-CoV was determined by calculating the percentage of nucleocapsid-positive cells in five randomly selected fields using Metamorph software. Presence of anti-Spike serum increased infectivity of SARS-CoV by 3-4-fold in macrophages of two out of three donors. Note that the ordinate's scale for Donor 3 is different for ease of visualization. Results are shown as means \pm SEM.

structures as FcyRIIB1. Our findings indicate that all Fc $\gamma$ RII constructs exhibited detectable expression of FcyRII (dark grey) in ST486 cells in comparison to isotype control (light grey) (Figure 5B). We then tested the ability of the various constructs to bind purified antiSpike IgG-SARS-CoVpp immune complexes and observed that all ST486 transfectants were able to bind immune complexes (Figure 5C). Finally we investigated whether any difference in susceptibility to SARS-CoVpp ADE of infection was conferred by different Fc $\gamma$ RII constructs. When immune complexes formed by $5 \mu \mathrm{g} / \mathrm{mL}$ of purified mouse anti-Spike IgG (the concentration at which the highest infection level was observed in Raji cells) and SARS-CoVpp were added to FcyRII-expressing ST486 cells, all four transfectants expressing wildtype Fc $\gamma$ RII forms (cf. Fc $\gamma$ RIIA-H vs. Fc $\gamma$ RIIA-R, and FcyRIIB1 vs. Fc $\gamma$ RIIB2, corresponding to constructs 1, $5,9,10$, respectively) were infected (Figure 5D), with FcyRIIA-expressing ST486 being more prone to infection than FcyRIIB (cf, constructs 1 and 5 with 9). All the endodomain-truncated constructs (Fc $\gamma$ RIIA-H. $\Delta \mathrm{IC}$, FcyRIIA-R. $\Delta \mathrm{IC}$ and Fc $\gamma$ RIIB. $\Delta \mathrm{IC}$, corresponding to constructs $2,6,11$ respectively) were not susceptible to $\mathrm{ADE}$ of infection, indicating that binding of anti-Spike
IgG-SARS-CoVpp immune complexes was not sufficient to mediate entry and that the signaling-competent endodomain was required. However, not all chimeric constructs were able to sustain ADE of infection, suggesting that domain swapping may have partially interfered with signal transduction. Thus only chimeras with FcyRIIA-H ectodomain and FcyRIIB1 endomain, or with FcyRIIB ectodomain and FcyRIIA endomain, exhibited a statistically significant ADE of infection (Figure 5D). This cannot be explained by differences in surface expression or binding of opsonized pseudoparticles, as FcyRIIB.EC/ IIA.IC (viz., construct 12) showed robust ADE despite one of the lowest binding ability of immune-complexes.

\section{Discussion}

The possibility that immune response to pathogens may have also deleterious effects on the host homeostasis has been the focus of several studies. For example, the hyper-induction of cytokines following avian influenza infection has been implicated in the severity of the disease [23] and infection of cells by ADE has been known to occur for several viral diseases $[20,21]$. Here we demonstrate that anti-Spike antibody potentiates infection 


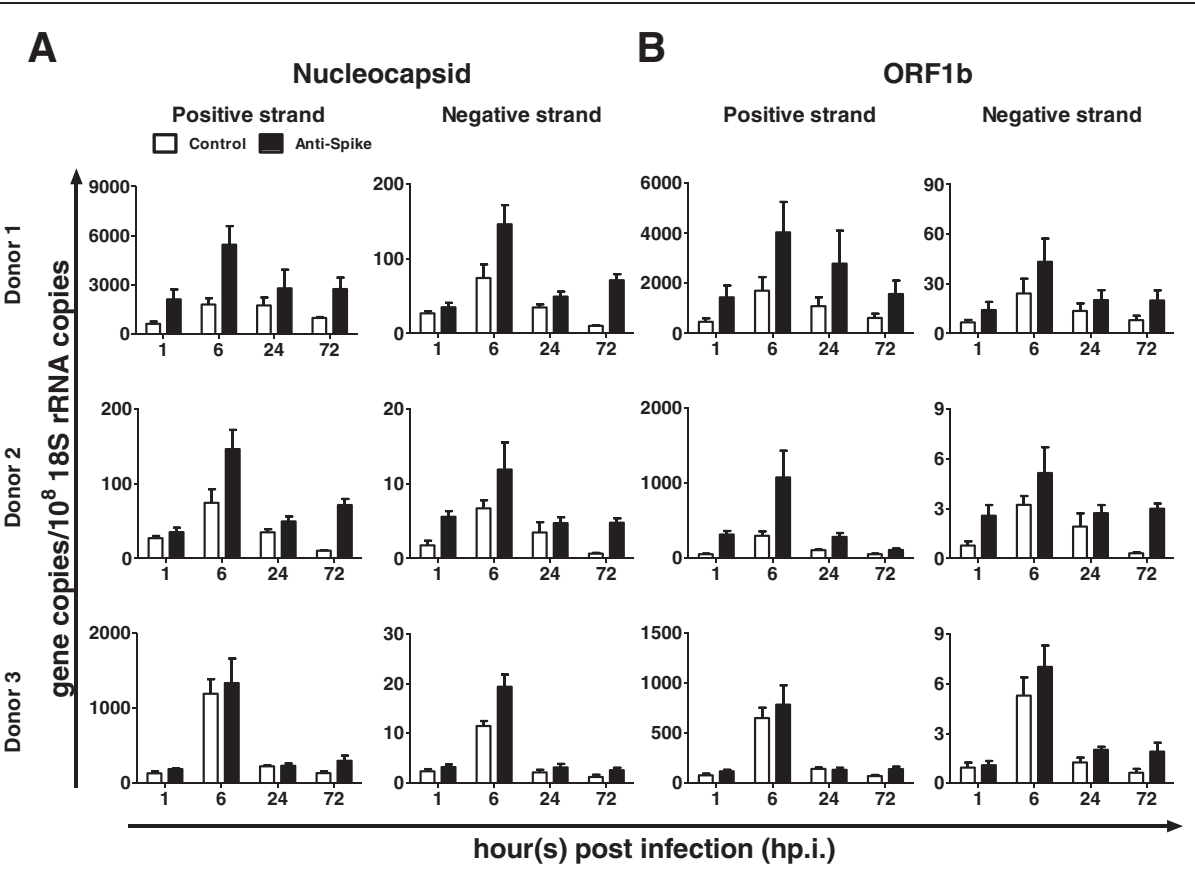

Figure 3 Nucleocapsid and ORF1b gene expression in SARS-CoV infected human macrophages. Monocyte-derived macrophages from three independent donors were infected with SARS-CoV as described in the legend to Figure 2 in the presence of anti-Spike (black bars) or control serum (white bars). Positive and negative RNA strands were determined for SARS-CoV nucleocapsid (A) and ORF1b (B) at the specified time points (hours) post infection (h.p.i.) using real-time qPCR. Data are shown as the number of viral RNA copies normalized to that of $10^{8}$ copies of 185 rRNA in the corresponding sample. Overall, RNA levels were higher in infected cells in presence of anti-Spike compared to control serum. Results are shown as means \pm SEM of four measurements from two separate runs for each donor and gene.

of human primary immune cells by SARS-CoVpp and replication-competent SARS-coronavirus.

Although we unambiguously obtained evidence of ongoing infection (e.g., de novo synthesis of the structural viral protein $\mathrm{N}$ ), ADE-infected macrophages did not support productive replication of SARS-CoV and, after initiation of viral gene transcription and viral protein synthesis, the replication process stalled ultimately ending in an abortive viral cycle without detectable release of progeny virus. Abortive replication of SARS-CoV into macrophages has already been documented [24] but, at variance with this previous report in which $90 \%$ of the macrophages were infected by SARS-CoV in the absence of immune-serum (MOI $=1-2)$, we observed a much lower infection rate (about 5-7\%). One possibility is that such discrepancy may be due to difference of time of sampling ( 6 hours in our study versus 15 hours in Cheung's study) and the protocol used for in vitro differentiation (viz., macrophages were differentiated in the presence of fetal calf serum in our study, and autologous plasma was removed two days prior to infection in ref. [8]), leading to difference in infectivity of the cells observed in the studies. Alternatively, we should also consider that the readout of the pseudo-particle experiments was the expression of the luciferase reporter gene, which is under the control of the HIV backbone.
This may lead to higher level of protein expression when compared to the abortive replication that follows SARS-CoV infection of macrophages. Thus, the difference may be, in part due to the inability to detect low amounts of Spike protein by immunofluorescence and the difference in sensitivity of the two methods. Of note, the antiSpike mediated entry is specific for Spike-pseudotyped particles, as shown in Figure 1 of [16].

Because clinical observations have reported poor disease outcomes in early seroconverted SARS patients [25-27], it would be of interest to test SARS patient sera collected at different time-points after SARS onset. However, we have been unable thus far to conduct conclusive assays on a well characterized serum library; moreover, we have to be cognizant of the possibility that ADE may only occur within a narrow window during the course of an infection and only in a subset of infected patients. The alternative possibility that internalization by macrophages may in fact represent an additional mechanism to control viral spread requires further investigation.

In general, studies aiming at better understanding antibody-dependent enhancement of viral infections are focusing on either identifying the (immune) receptor(s) and/or serum component(s) allowing penetration of the pathogen into the target cell, also known as extrinsic $\mathrm{ADE}$, or the outcome response(s) of the target cell 


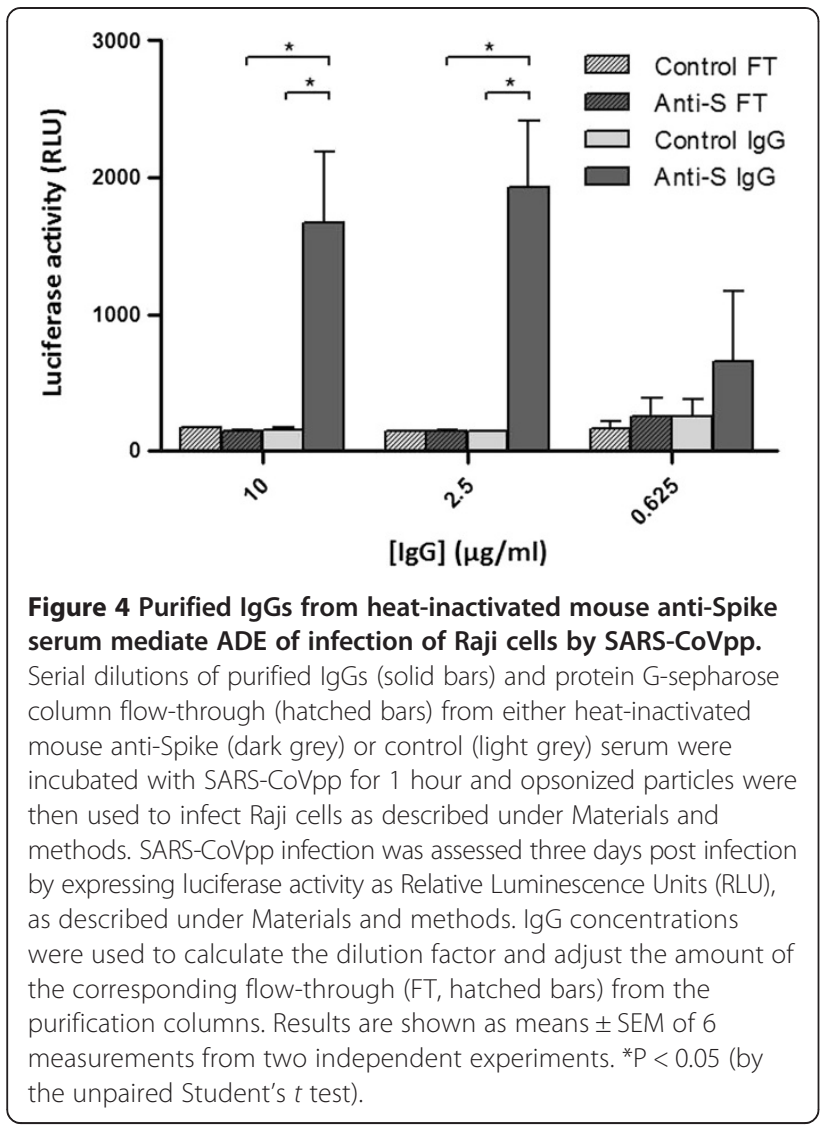

downstream to ADE of infection - or intrinsic ADE $[20,21,28]$. Our previous results demonstrated that only Fc $\gamma$ RIIA and, to a lesser extent, Fc $\gamma$ RIIB1 triggered infection by SARS-CoVpp in presence of anti-Spike serum [16]. Although it would have been desirable to perform $\mathrm{Fc} \gamma \mathrm{R}$ blocking experiments also in macrophages, coexpression of all FcyRs in these cells $[29,30]$ would cause blocking antibodies to bind not only to the targeted $\mathrm{Fc} \gamma \mathrm{R}$ via their Fab portions, but also to other $\mathrm{Fc} \gamma \mathrm{R}$ via their Fc portion making both FcyRs unavailable for interaction with opsonized pseudoparticles and, consequently, would prevent unambiguous interpretation of the results. We therefore investigated the molecular/signaling requirement underlying Fc $\gamma$ RII-mediated infection by SARS-CoV and assessed the relative contribution of the extracellular versus the transmembrane and intracellular domains of the Fcy receptor II family members in mediating ADE of infection. The extracellular IgG-binding domains of human FcyRIIA and Fc $\gamma$ RIIB are closely related, with $78 \%$ of homology at the amino acid level. Nonetheless, these 2 receptors have distinct abilities and affinities for the binding of immunoglobulins [31]. Moreover, Fc $\gamma$ RIIA carries an immunoreceptor tyrosinebased activation motif (ITAM) whereas FcyRIIB carries an immunoreceptor tyrosine-based inhibitory motif (ITIM), which confer IgG receptors different effector properties
$[29,30,32]$. Altogether, our results demonstrate that binding of SARS-CoVpp to cells via the extracellular domain of FcyRs is not sufficient to trigger ADE of infection as entry requires an intact intracellular domain. Indeed, in spite of roughly similar expression level at the cell surface compared to wild type FcyRII, all mutated Fc $\gamma$ RII receptors having truncation of their intracellular domain (Fc $\gamma \mathrm{RII} \Delta \mathrm{IC}$ ) became unable to trigger $\mathrm{ADE}$ of infection while retaining significant level of ligand-bind ability. The results obtained with chimeric constructions where the whole intracellular domain of Fc $\gamma$ RIIA and Fc $\gamma$ RIIB were swapped lend further support to this interpretation. Of note, the transmembrane and intracellular domains appeared to impart susceptibility to infection of their parental FcyRII. Thus, wild-type FcyRIIA elicited greater ADE than FcyRIIB and grafting the cytoplasmic portion of FcyRIIB reduced susceptibility to ADE of the chimeras with an extracellular FcyRIIA domain to levels comparable to those observed for the Fc $\gamma$ RIIA truncated mutants.

However, the relationship between internalization of immune complexes and ADE of infection by SARS-CoV via FcyRIIs appears to be a complex process. Thus, FcyRIIB2 has been shown to mediate internalization of immune complexes at a faster rate than FcyRIIA [33], whereas we found that ADE of infection via FcyRIIA was more prominent than with FcyRIIB. Recently, involvement of downstream signaling triggered by $\mathrm{Fc} \gamma \mathrm{Rs}$ activation has been evaluated with respect to ADE of dengue virus infection [34]. Thus, abrogation of FcyRI and FcyRII signaling competency was associated with significant impairment of phagocytosis, but only the signaling-incompetent Fc $\gamma$ RI become unable to trigger ADE of dengue virus. Conversely, no discernible effect on dengue virus immune complex infectivity was observed for both wild type and signaling incompetent FcyRIIA. These findings point to fundamental differences between Fc $\gamma$ RIA and FcyRIIA with respect to their immuneenhancing capabilities and suggest that different mechanisms of dengue virus immune complex internalization may operate between these FcyRs [34].

\section{Conclusions}

Altogether our results demonstrate that, in presence of vaccine-elicited antiviral antibodies, SARS-CoV displays an altered tropism toward primary human immune cells, which do not express the conventional virus receptor and are otherwise refractory to the virus. A number of SARS vaccine candidates have been tested in experimental animal models [35,36], many of them based on the viral Spike glycoprotein previously identified as the most immunogenic antigen inducing neutralizing and protective antibodies $[14,15,37,38]$. Of note, some vaccines against animal coronaviruses have been also generated, but their development has proven difficult due to immune 


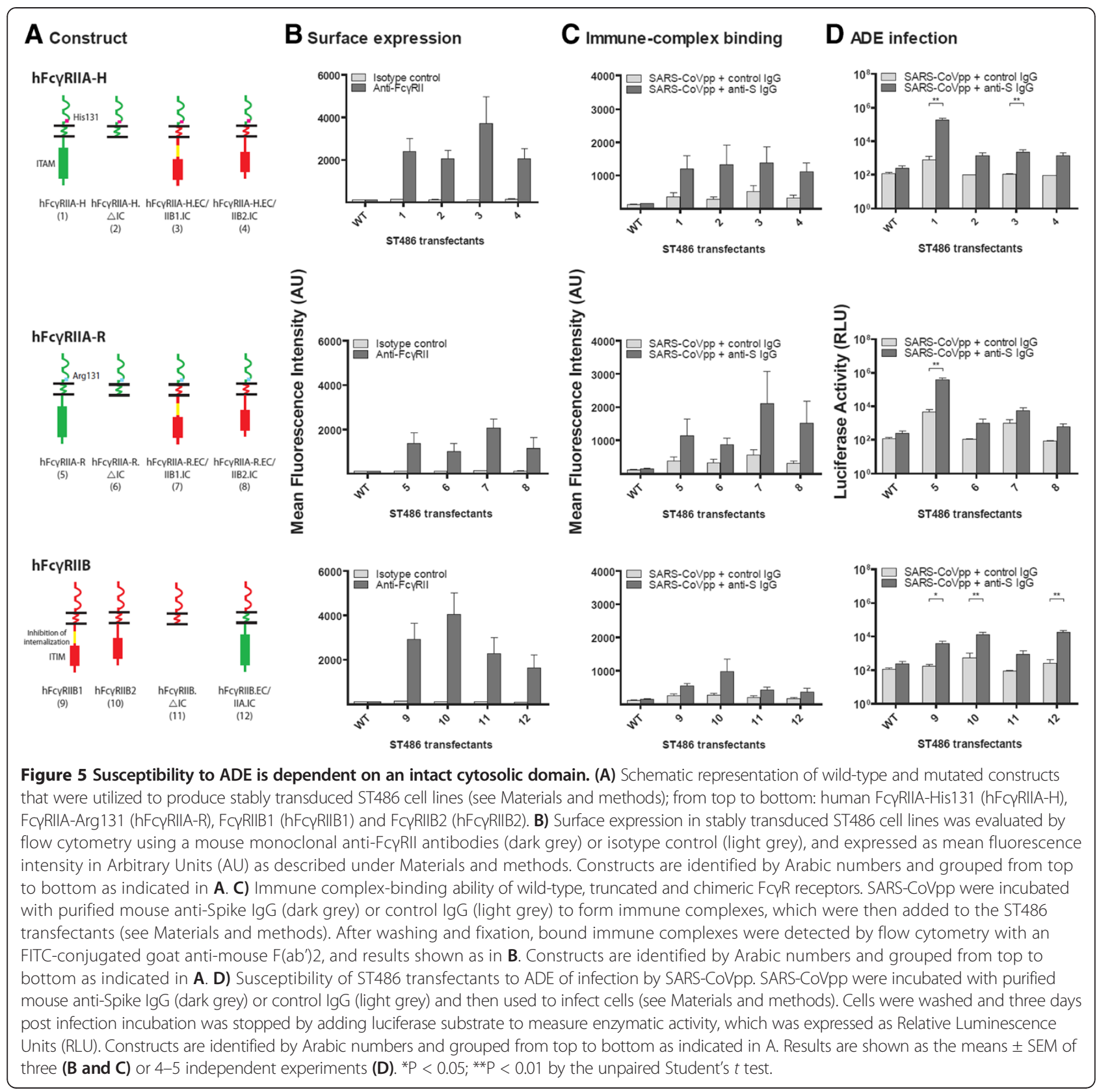

enhancement of disease in vaccinated recipients [39-41]. Despite the fact that this alternative infection pathway appears to have a limited impact, it remains of interest to appreciate the cost of antibody-mediated SARS-CoV infection on the functionality of the target cells, in order to have a broad understanding of the tropism and pathogenesis of the virus and evaluate potential pitfalls associated with immunization against human coronaviruses. This aspect is gaining more relevance as the emergence of the MERS-CoV further indicates that the availability of vaccines targeting this group of viruses, which have demonstrated the ability to jump species, is one of the few options available to prevent the spread of infections causing severe diseases with high mortality in humans [42].

\section{Materials and methods}

\section{Cell lines and expression vectors}

The following cell lines used in the study were obtained from the American Type Culture Collection (ATCC; Manassas, VA, USA): HEK293T (human kidney epithelial cells; CRL-11268), Raji (Burkitt's lymphoma/B lymphoblast), ST486 (Burkitt's lymphoma/B lymphoblast lacking expression of FcyR; CRL-1647). HEK293T cells were cultured in DMEM supplemented with 10\% heat-inactivated fetal bovine serum (FBS), $0.6 \mathrm{mg} / \mathrm{l}$ penicillin and $60 \mathrm{mg} / \mathrm{l}$ 
streptomycin, whereas hematopoietic cells were grown in RPMI-1640 supplemented with 10\% heat-inactivated FBS, $1 \%$ non-essential amino-acids, $4 \mathrm{mM}$ L-glutamine, $1 \mathrm{mM}$ sodium pyruvate, $0.6 \mathrm{mg} / \mathrm{l}$ penicillin, $60 \mathrm{mg} / \mathrm{l}$ streptomycin, and $20 \mu \mathrm{M} 2-\beta$-mercaptoethanol (all from Invitrogen Life Technologies, Carlsbad, CA, USA). All cells were maintained at $37^{\circ} \mathrm{C}$ in a humidified atmosphere with $5 \%$ $\mathrm{CO}_{2}$ supply.

\section{Culture of human monocyte-derived macrophages}

The research protocol was approved by the Institutional Review Board of the University of Hong Kong/Hospital Authority Hong Kong West Cluster (UW09-375). Blood samples of healthy donors were obtained from the Hong Kong Red Cross Blood Transfusion Service. Human blood cells were isolated from buffy coats and monocyte-derived macrophages were generated in vitro using a modified protocol as previously described $[24,43]$. Briefly, mononuclear cells were isolated by a Ficoll-Paque density gradient (Pharmacia Biotech, Uppsala, Sweden) to remove erythrocytes, granulocytes, and cell debris. Monocytes were enriched by plastic adherence, harvested, seeded $\left(10^{6}\right.$ cells $\left./ \mathrm{ml}\right)$ on tissue culture plates and allowed to differentiate for 14 days in the presence of 5\% autologous human plasma and 1\% fetal calf serum before use. The purity of macrophages was consistently above $90 \%$, as ascertained by immunofluorescence staining for human CD68, a lysosomal glycoprotein that is highly expressed by macrophages and monocytes $[44,45]$.

\section{Production of anti-Spike immune serum}

BALB/c mice were immunized with recombinant SARSCoV Spike proteins adjuvanted with alum, as previously described $[15,16]$. Saline-injected mice served as controls. Serum was collected at day 55 post-immunization, heatinactivated for $30 \mathrm{~min}$ at $56^{\circ} \mathrm{C}$ and stored at $-20^{\circ} \mathrm{C}$ for subsequent use.

\section{Production and use of lentiviral particles pseudotyped with SARS-CoV Spike}

The protocol to produce SARS-CoV pseudotyped lentiviral particles expressing a luciferase reporter gene (SARSCoVpp) has been described elsewhere [17]. Following a purification step on 20\% sucrose cushion, the concentrated viral particles were titrated by ELISA for lentivirus-associated HIV-1 p24 protein according to the manufacturer's instruction (Cell Biolabs, Inc., San Diego, CA, USA), and stored at $-80^{\circ} \mathrm{C}$ until use. For ADE assays, heat-inactivated mouse anti-Spike or control serum was incubated for $1 \mathrm{hr}$ at $37^{\circ} \mathrm{C}$ with SARS-CoVpp. This inoculum was deposited on cells and infection proceeded for $1 \mathrm{hr}$ at $37^{\circ} \mathrm{C}$. Following repeated washing cells were incubated for additional 60-65 hours and then fixed in $4 \%$ paraformaldehyde (SigmaAldrich Inc., St. Louis, MO, USA) for immunofluorescence microscopy.

\section{Infection with replication-competent SARS-CoV}

Laboratory procedures involving replication-competent viruses were performed in biosafety level-3 containment (State Key Laboratory of Emerging Infectious Diseases, The University of Hong Kong). The SARS-CoV strain used (HK39849) is a clinical isolate [46], which was cultured in fetal rhesus kidney-4 (FRhK-4, ATCC code CRL-1688) cells. In ADE assays, heat-inactivated mouse anti-Spike or control serum was incubated for $1 \mathrm{~h}$ at $37^{\circ} \mathrm{C}$ with SARS-CoV and human monocyte-derived macrophages were infected at an MOI of 1 for $60 \mathrm{~min}$ at $37^{\circ} \mathrm{C}$. After repeated washings, cells were cultured with fresh medium (time 0) supplemented with $2 \%$ FBS for the indicated time points (hours) post infection (p.i.) and eventually either fixed in $4 \%$ paraformaldehyde (Sigma-Aldrich Inc.) for immunofluorescence microscopy, or resuspended in lysis buffer (RLT buffer, RNeasy RNA Mini kit; QIAGEN, Germantown, MD, USA) for real-time quantitative RT-PCR. Samples of cell culture supernatants harvested at different h.p.i. were also mixed with RLT buffer and processed as above for RT-PCR.

\section{Immunofluorescence microscopy}

Infectivity of replication-competent SARS-CoV was determined by indirect immunofluorescence with a mouse monoclonal antibody directed against SARS-CoV nucleocapsid protein (clone 4D11; a gift from Dr. Kwok-Hung Chan, Department of Clinical Microbiology, Queen Mary Hospital, Hong Kong), at a dilution of 1:200. Staining was revealed with a tetramethylrhodamine-5-(and-6)isothiocyanate (TRITC) conjugated goat anti-mouse antibody (Invitrogen Life Technologies) on an AxioObserver Z1 microscope (Carl Zeiss, Inc., Thornwood, New York, USA). Pictures taken from 5 randomly chosen fields at a magnification of $400 \mathrm{X}$ were acquired with an Axiocam MRm camera and analyzed with Metamorph software (Molecular Devices, Sunnyvale, CA, USA). Infectivity was determined as the percentage of cells expressing viral antigen. Similar staining procedures were employed for assessing infection by SARS-CoVpp, except for the use of direct immunofluorescence with a fluorescein isothiocyanate (FITC) conjugated goat monoclonal antibody specific for firefly luciferase (Rockland, Gilbertsville, PA, USA) at a dilution of 1:100.

\section{Real-time quantitative RT-PCR for viral gene expression}

RNA was extracted with the RNeasy RNA Mini kit (QIAGEN), according to the manufacturer's recommendations; concentration and purity of RNA were measured by standard optical methods. Reverse transcription was performed on total RNAs with Superscript III reverse transcriptase as specified by the manufacturer (Invitrogen Life Technologies). For quantification of SARS-CoV gene copies, cDNA was generated in separate reactions in 
presence of either forward or reverse primers specific for the nucleocapsid and ORF1b genes (Table 1) that amplified negative and positive strand viral RNAs, respectively. This assay allows distinguishing between signals generated by entry of input virus from downstream events reflecting an active replication process [47]. Specific primers (Table 1) and TaqMan Minor Groove Binder probes used for detection of SARS-CoV nucleocapsid gene have been previously described [48]. However, it should be noted that the primer set used for the nucleocapsid gene could also detect the negative strand of the viral genomic RNA and could not distinguish it from sub-genomic material. The qPCR assay was carried out in a final volume of $20 \mu \mathrm{l}$ and the fluorescence signal was detected with a LightCycler 480-II (Roche Applied Science, Mannheim, Germany) programmed as follows: $95^{\circ} \mathrm{C}$ for $10 \mathrm{~min}$, followed by 45 cycles of $95^{\circ} \mathrm{C}$ for $10 \mathrm{sec}, 60^{\circ} \mathrm{C}$ for $30 \mathrm{sec}$, and $72^{\circ} \mathrm{C}$ for $1 \mathrm{sec}$. Results were expressed as the number of target copies per $10^{8}$ copies of the $18 \mathrm{~S}$ rRNA gene, which was used to normalize results. To ensure the consistency of qPCR measurements over the time period of the study, the same batches of primers and probes were employed. The qPCR results were considered valid when the efficiency of the standard curve was between 1.9 to 2.1 and the $R^{2}$ value was greater than 0.99 .

\section{Purification of IgGs from mouse serum}

IgGs was purified from immunized and control mice using protein G-sepharose (GE Healthcare, Little Chalfont, United Kingdom) according to the manufacturer's recommendations. The purity of the IgG fraction was checked by silver staining following gel electrophoresis and the concentration of anti-Spike IgG determined by ELISA.

\section{Construction of lentiviral vectors for wildtype, endodomain-truncated and chimeric forms of FcyRII (hCD32)}

The strategy to produce plasmids for wild-type human IgG receptors $(\mathrm{Fc} \gamma \mathrm{Rs})$ consisted in replacing the enhanced green fluorescent protein (eGFP) gene from the bicistronic vector pCHMWS-eGFP_IRES_Hygromycin (a kind gift from Drs. Rik Gijsbers and Zeger Debyser, Katholieke Universiteit Leuven, Belgium) with the coding sequences for FcyRIIA (hCD32a) isoforms (FcyRIIA.R131 and FgRIIA. H131 GenBank accession No. NM_021642) and FcyRIIB1 (hCD32b; GenBank accession No. AF543826) flanked by BglII and SalI sites, as described elsewhere [16]. The synthetic sequences (GeneArt, Regensburg, Germany) were inserted into the original transfer plasmid to yield wildtype constructs. pCHMWS-FcyRIIB2_IRES_Hygromycin was constructed by swapping the intracellular domain of FcyRIIB2, obtained from RT-PCR amplification of the desired sequence from polyclonal Raji cDNA, with the corresponding region of the pCHMWS-FcyRIIB1_IRES_Hygromycin construct. Wild-type constructs were subsequently used to generate truncated and chimeric forms of FcyRIIs by standard techniques (see Figure 5A for a schematic representation of the mutants tested). All plasmids were sequenced by the Centre for Genomic Sciences of the University of Hong Kong.

Generation of stable ST486 cell lines expressing wild-type and mutated $F c \gamma R s$ using lentiviral particle-based gene transduction

Cell lines were generated by transduction of monoclonal ST486 cells with vesicular stomatitis virus (VSV) G pseudotyped lentiviral particles bearing the specified transgene as previously described [16]. At 2 days post-infection, cell surface expression of the FcyRs was monitored by flow cytometry and cells were subsequently cultured in selective medium containing $250 \mu \mathrm{g} / \mathrm{ml}$ hygromycin (Invitrogen Life Technologies) when appropriate. Finally, several monoclonal cell lines for each construct were isolated and expression of the transgene was confirmed by flow cytometry.

\section{Evaluation of FcyR expression on ST486 transfected cell lines by flow cytometry}

Expression of FcyRIIs was evaluated by flow cytometry as described in [16]. The following mouse MAbs were

Table 1 Sequences of primers and probes used in real-time qPCR assay and CDNA synthesis

\begin{tabular}{llll}
\hline Gene & Sequences & Amplification product (bp) & GeneBank accession number \\
\hline 18 rRNA & (F) 5'-CggAggTTCgAAgACgATCA & 90 & NR_003286 \\
Nucleocapsid & (R) 5'-ggCgggTCATgggAATAAC & & AY278491 \\
& (P) 5'(HEX) ATACCgTCgTAgTTCCgACCA (BHQ) & & \\
(F) 5'-ACCAgAATggAggACgCAATg & 85 & AY278491 \\
ORF1b & (R) 5'-gCTgTgAACCAAgACgCAgTATTAT & & \\
& (P) 5'(FAM) ACCCCAAggTTACCC (NFQ) & 68 & \\
& (F) 5'-CAgAACgCTgTAgCTTCAAAATCT & & \\
\hline
\end{tabular}


used: 3 G8 anti-hCD16, FLI8.26 for hCD32, and 10.1 anti-hCD64 (all from BD PharMingen, Frankin Lakes, NJ, USA); MOPC-21 (IgG1, к) or MPC-11 (IgG2b, к) isotype controls (both from BioLegend, San Diego, CA, USA). Cells were washed and primary antibody binding was revealed by staining on ice for $30 \mathrm{~min}$ with FITCconjugated goat anti-mouse antibodies (Jackson ImmunoResearch, West Grove, PA, USA). Data were collected from at least 10,000 singlet living cells on a LSRII flow cytometer (BD Biosciences, San Jose, CA, USA) and analyzed using FlowJo software (TreeStar, Ashland, OR, USA).

\section{Binding of immune complexes to FcyRII}

SARS-CoVpp-IgG immune complexes were obtained by incubating SARS-CoVpp with $30 \mu \mathrm{g} / \mathrm{ml}$ of either purified mouse anti-Spike or control IgG at $37^{\circ} \mathrm{C}$ for $1 \mathrm{hr}$. The mixture was then quickly chilled on ice for $10 \mathrm{~min}$ and added $(100 \mu \mathrm{l} /$ well $)$ to ST486 cells $\left(3 \times 10^{5}\right.$ cells/well), which had been previously stained with $0.1 \%$ fixable viability dye eFluor 660 (eBioscience, San Diego, CA, USA). Following a $1 \mathrm{hr}$ incubation on ice, cells were washed twice with cold PBS, fixed with 1\% paraformaldehyde for $20 \mathrm{~min}$ on ice and immune complex binding was revealed by staining with $5 \mu \mathrm{g} / \mathrm{ml}$ FITC-conjugated goat anti-mouse $\mathrm{F}(\mathrm{ab})_{2}$ (Jackson ImmunoResearch) at $4^{\circ} \mathrm{C}$ for $30 \mathrm{~min}$. Data were collected and analysed as described above.

\section{Statistical analysis}

Results are shown as means \pm SEM of the indicated number of observations. Statistical difference between groups was determined by the unpaired Students's $t$-test with a 0.05 significance level.

\begin{abstract}
Abbreviations
ACE2: Angiotensin-converting enzyme-2; ADE: Antibody-dependent enhancement; DC-SIGN: Dendritic cell specific intercellular adhesion molecule 3-grabbing non-integrin; eGFP: Enhanced green fluorescent protein; FITC: Fluorescein isothiocyanate; h.p.i.: Hours post infection; L-SIGN: Liver/lymph node-specific intercellular adhesion molecule-3-grabbing integrin; ITAM: Immunoreceptor tyrosine-based activation motif; ITIM: Immunoreceptor tyrosine-based inhibitory motif; MERS-CoV: Middle East respiratory syndrome coronavirus; MOI: Multiplicity of infection; RTPCR: Reverse transcriptase-polymerase chain reaction; SARS-CoV: Severe acute respiratory syndrome coronavirus; SARS-CoVpp: Evere acute respiratory syndrome coronavirus pseudo-particles; TRITC: Tetramethylrhodamine-5-(and-6)isothiocyanate; VSV: Vesicular stomatitis virus.
\end{abstract}

\section{Competing interests}

The authors declare that they have no competing interests.

\section{Authors' contributions}

MSY, NHLL, PHL, HHYL performed cell culture, molecular biology, microscopy, and flow cytometry studies; CYC performed the experiments with SARS-CoV in the BSL-3 lab; MJ, MSY, NHLL, MD, JSMP, RB participated in the design of the study and analysis of the data; MJ and RB wrote the manuscript. All authors commented and approved the final version of the manuscript.

\section{Acknowledgements}

The HKU-Pasteur Research Pole is a member of the Institut Pasteur International Network. We wish to thank Lewis Siu (HKU-Pasteur Research Pole) for sharing with us his stock of SARS-CoV Spike lentiviral particles when it was most needed. We are grateful to Kwok Hung Chan (Queen Mary Hospital, Pokfulam, Hong Kong) for the gift of the mouse monoclonal antibody (4D11) specific for the SARS-CoV nucleoprotein, and Rik Gijsbers and Zeger Debyser (Katholieke Universiteit Leuven, Belgium) for providing the bicistronic retroviral vector used to establish the FcyR-expressing stable cell lines. Many thanks to Suki Lee, Chris Mok and members of the HKU-Pasteur Research Pole for their expert advice and critical reading of the manuscript. M.S. Yip was a PhD and Nancy H.L. Leung was an MPhil student supported in part by The University of Hong Kong. This work was supported by the Research Fund for the Control of Infectious Disease (RFCID; project no. 09080872) of the Hong Kong Government and by the RESPARI project of the Institut Pasteur International Network.

\section{Author details}

${ }^{1}$ HKU-Pasteur Research Pole and Center of Influenza Research, School of Public Health, LKS Faculty of Medicine, The University of Hong Kong, Hong Kong, Hong Kong SAR. ${ }^{2}$ Department of Microbiology, LKS Faculty of Medicine, The University of Hong Kong, Hong Kong, Hong Kong SAR. ${ }^{3}$ Departement of Immunology, Institut Pasteur, Paris, France. ${ }^{4}$ Centre d'Immunologie de Marseille-Luminy, Inserm U1104, Marseille, France. ${ }^{5}$ Department of Cell Biology and Infection, Institut Pasteur, Paris, France.

Received: 21 November 2013 Accepted: 22 April 2014

Published: 6 May 2014

\section{References}

1. Peiris JS, Guan Y, Yuen KY: Severe acute respiratory syndrome. Nat Med 2004, 10:S88-597.

2. Writing Committee of the Second World Health Organization Consultation on Clinical Aspects of Human Infection with Avian Influenza AV, AbdelGhafar AN, Chotpitayasunondh T, Gao Z, Hayden FG, Nguyen DH, de Jong MD, Naghdaliyev A, Peiris JS, Shindo N, Soeroso S, Uyeki TM: Update on avian influenza A (H5N1) virus infection in humans. N Engl J Med 2008, 358:261-273.

3. Michaelis M, Doerr HW, Cinatl J Jr: An influenza A H1N1 virus revival pandemic $\mathrm{H} 1 \mathrm{N1} / 09$ virus. Infection 2009, 37:381-389.

4. van Boheemen S, de Graaf M, Lauber C, Bestebroer TM, Raj VS, Zaki AM, Osterhaus AD, Haagmans BL, Gorbalenya AE, Snijder EJ, Fouchier RA: Genomic characterization of a newly discovered coronavirus associated with acute respiratory distress syndrome in humans. MBio 2012, 3:e00473-12.

5. Zaki AM, van Boheemen S, Bestebroer TM, Osterhaus AD, Fouchier RA: Isolation of a novel coronavirus from a man with pneumonia in Saudi Arabia. N Engl J Med 2012, 367:1814-1820.

6. Gao R, Cao B, Hu Y, Feng Z, Wang D, Hu W, Chen J, Jie Z, Qiu H, Xu K, Xu X, Lu H, Zhu W, Gao Z, Xiang N, Shen Y, He Z, Gu Y, Zhang Z, Yang Y, Zhao X, Zhou L, Li X, Zou S, Zhang Y, Li X, Yang L, Guo J, Dong J, Li Q, et al: Human infection with a novel avian-origin influenza $A$ (H7N9) virus. N Engl J Med 2013, 368:1888-1897.

7. Liu D, Shi W, Shi Y, Wang D, Xiao H, Li W, Bi Y, Wu Y, Li X, Yan J, Liu W, Zhao G, Yang W, Wang Y, Ma J, Shu Y, Lei F, Gao GF: Origin and diversity of novel avian influenza A H7N9 viruses causing human infection: phylogenetic, structural, and coalescent analyses. Lancet 2013, 381:1926-1932.

8. Gu J, Gong E, Zhang B, Zheng J, Gao Z, Zhong Y, Zou W, Zhan J, Wang S, Xie Z, Zhuang H, Wu B, Zhong H, Shao H, Fang W, Gao D, Pei F, Li X, He Z, Xu D, Shi X, Anderson VM, Leong AS: Multiple organ infection and the pathogenesis of SARS. J Exp Med 2005, 202:415-424.

9. Li L, Wo J, Shao J, Zhu H, Wu N, Li M, Yao H, Hu M, Dennin RH: SARScoronavirus replicates in mononuclear cells of peripheral blood (PBMCs) from SARS patients. J Clin Virol 2003, 28:239-244.

10. Yilla M, Harcourt BH, Hickman CJ, McGrew M, Tamin A, Goldsmith CS, Bellini WJ, Anderson LJ: SARS-coronavirus replication in human peripheral monocytes/macrophages. Virus Res 2005, 107:93-101.

11. Hamming I, Timens W, Bulthuis ML, Lely AT, Navis G, van Goor H: Tissue distribution of ACE2 protein, the functional receptor for SARS coronavirus. A first step in understanding SARS pathogenesis. J Pathol 2004, 203:631-637.

12. Harmer D, Gilbert M, Borman R, Clark KL: Quantitative mRNA expression profiling of $A C E 2$, a novel homologue of angiotensin converting enzyme. FEBS Lett 2002, 532:107-110. 
13. Jeffers SA, Tusell SM, Gillim-Ross L, Hemmila EM, Achenbach JE, Babcock GJ, Thomas WD Jr, Thackray LB, Young MD, Mason RJ, Ambrosino DM, Wentworth DE, Demartini JC, Holmes KV: CD209L (L-SIGN) is a receptor for severe acute respiratory syndrome coronavirus. Proc Natl Acad Sci U S A 2004, 101:15748-15753.

14. Yang ZY, Huang Y, Ganesh L, Leung K, Kong WP, Schwartz O, Subbarao K, Nabel GJ: pH-dependent entry of severe acute respiratory syndrome coronavirus is mediated by the spike glycoprotein and enhanced by dendritic cell transfer through DC-SIGN. J Virol 2004, 78:5642-5650

15. Kam YW, Kien F, Roberts A, Cheung YC, Lamirande EW, Vogel L, Chu SL, Tse J, Guarner J, Zaki SR, Subbarao K, Peiris M, Nal B, Altmeyer R: Antibodies against trimeric $S$ glycoprotein protect hamsters against SARS-CoV challenge despite their capacity to mediate FcgammaRIl-dependent entry into B cells in vitro. Vaccine 2007, 25:729-740.

16. Jaume M, Yip MS, Cheung CY, Leung HL, Li PH, Kien F, Dutry I, Callendret B, Escriou N, Altmeyer R, Nal B, Daëron M, Bruzzone R, Peiris JS: Anti-severe acute respiratory syndrome coronavirus spike antibodies trigger infection of human immune cells via a $\mathrm{pH}$ - and cysteine protease-independent FcgammaR pathway. J Virol 2011, 85:10582-10597.

17. Kam YW, Okumura Y, Kido H, Ng LF, Bruzzone R, Altmeyer R: Cleavage of the SARS coronavirus spike glycoprotein by airway proteases enhances virus entry into human bronchial epithelial cells in vitro. PLoS One 2009, 4:e7870.

18. Olsen CW, Corapi WV, Ngichabe CK, Baines JD, Scott FW: Monoclonal antibodies to the spike protein of feline infectious peritonitis virus mediate antibody-dependent enhancement of infection of feline macrophages. J Virol 1992, 66:956-965.

19. Sauter $P$, Hober $D$ : Mechanisms and results of the antibody-dependent enhancement of viral infections and role in the pathogenesis of coxsackievirus B-induced diseases. Microbes Infect 2009, 11:443-451.

20. Sullivan NJ: Antibody-mediated enhancement of viral disease. Curr Top Microbiol Immunol 2001, 260:145-169.

21. Takada A, Kawaoka Y: Antibody-dependent enhancement of viral infection: molecular mechanisms and in vivo implications. Rev Med Virol 2003, 13:387-398.

22. lerino FL, Hulett MD, McKenzie IF, Hogarth PM: Mapping epitopes of human Fc gamma RII (CDw32) with monoclonal antibodies and recombinant receptors. J Immunol 1993, 150:1794-1803.

23. Peiris JS, Poon LM, Nicholls JM, Guan Y: The role of influenza virus gene constellation and viral morphology on cytokine induction, pathogenesis, and viral virulence. Hong Kong Med J 2009, 15:21-23.

24. Cheung $\mathrm{CY}$, Poon LL, Ng $\mathrm{H}$, Luk W, Sia SF, Wu MH, Chan KH, Yuen KY, Gordon S, Guan Y, Peiris JS: Cytokine responses in severe acute respiratory syndrome coronavirus-infected macrophages in vitro: possible relevance to pathogenesis. J Virol 2005, 79:7819-7826.

25. Ho MS, Chen WJ, Chen HY, Lin SF, Wang MC, Di J, Lu YT, Liu CL, Chang SC, Chao CL, King CC, Chiou JM, Su IJ, Yang JY: Neutralizing antibody response and SARS severity. Emerg Infect Dis 2005, 11:1730-1737.

26. Lee N, Chan PK, Ip M, Wong E, Ho J, Ho C, Cockram CS, Hui DS: Anti-SARSCoV IgG response in relation to disease severity of severe acute respiratory syndrome. J Clin Virol 2006, 35:179-184.

27. Zhang L, Zhang F, Yu W, He T, Yu J, Yi CE, Ba L, Li W, Farzan M, Chen Z, Yuen $K Y$, Ho D: Antibody responses against SARS coronavirus are correlated with disease outcome of infected individuals. J Med Virol 2006, 78:1-8.

28. Halstead SB, Mahalingam S, Marovich MA, Ubol S, Mosser DM: Intrinsic antibody-dependent enhancement of microbial infection in macrophages: disease regulation by immune complexes. Lancet Infect Dis 2010, 10:712-722.

29. Daeron M: Fc receptor biology. Annu Rev Immunol 1997, 15:203-234.

30. Nimmerjahn F, Ravetch JV: Fcgamma receptors as regulators of immune responses. Nat Rev Immunol 2008, 8:34-47.

31. Bruhns $P$, lannascoli B, England P, Mancardi DA, Fernandez N, Jorieux S, Daeron M: Specificity and affinity of human Fcgamma receptors and their polymorphic variants for human IgG subclasses. Blood 2009, 113:3716-3725.

32. Daeron $M$, Vivier E: Biology of immunoreceptor tyrosine-based inhibition motif-bearing molecules. Curr Top Microbiol Immunol 1999, 244:1-12.

33. Zhang CY, Booth JW: Differences in endocytosis mediated by FcgammaRIIA and FcgammaRIIB2. Mol Immunol 2011, 49:329-337.
34. Rodrigo WW, Jin X, Blackley SD, Rose RC, Schlesinger JJ: Differential enhancement of dengue virus immune complex infectivity mediated by signaling-competent and signaling-incompetent human Fcgamma RIA (CD64) or FcgammaRIIA (CD32). J Virol 2006, 80:10128-10138.

35. Du L, He Y, Zhou Y, Liu S, Zheng BJ, Jiang S: The spike protein of SARS-CoV-a target for vaccine and therapeutic development. Nat Rev Microbiol 2009, 7:226-236.

36. Enjuanes L, Dediego ML, Alvarez E, Deming D, Sheahan T, Baric R: Vaccines to prevent severe acute respiratory syndrome coronavirus-induced disease. Virus Res 2008, 133:45-62.

37. Bisht H, Roberts A, Vogel L, Bukreyev A, Collins PL, Murphy BR, Subbarao K, Moss $B$ : Severe acute respiratory syndrome coronavirus spike protein expressed by attenuated vaccinia virus protectively immunizes mice. Proc Natl Acad Sci U S A 2004, 101:6641-6646.

38. Buchholz UJ, Bukreyev A, Yang L, Lamirande EW, Murphy BR, Subbarao K, Collins PL: Contributions of the structural proteins of severe acute respiratory syndrome coronavirus to protective immunity. Proc Natl Acad Sci U S A 2004, 101:9804-9809.

39. Huisman W, Martina BE, Rimmelzwaan GF, Gruters RA, Osterhaus AD: Vaccine-induced enhancement of viral infections. Vaccine 2009, 27:505-512

40. Saif LJ: Animal coronavirus vaccines: lessons for SARS. Dev Biol (Basel) 2004, 119:129-140.

41. Vennema H, de Groot RJ, Harbour DA, Dalderup M, Gruffydd-Jones T, Horzinek MC, Spaan WJ: Immunogenicity of recombinant feline infectious peritonitis virus spike protein in mice and kittens. Adv Exp Med Biol 1990, 276:217-222.

42. Perlman S: The middle East respiratory syndrome-how worried should we be? MBio 2013, 4:e00531-13

43. Cheung CY, Poon LL, Lau AS, Luk W, Lau YL, Shortridge KF, Gordon S, Guan $Y$, Peiris JS: Induction of proinflammatory cytokines in human macrophages by influenza $A(\mathrm{H} 5 \mathrm{~N} 1)$ viruses: a mechanism for the unusual severity of human disease? Lancet 2002, 360:1831-1837.

44. Nicholls JM, Butany J, Poon LL, Chan KH, Beh SL, Poutanen S, Peiris JS, Wong M: Time course and cellular localization of SARS-CoV nucleoprotein and RNA in lungs from fatal cases of SARS. PLOS Med 2006, 3:e27.

45. Holness $\mathrm{CL}$, Simmons DL: Molecular cloning of CD68, a human macrophage marker related to lysosomal glycoproteins. Blood 1993, 81:1607-1613.

46. Peiris JS, Chu CM, Cheng VC, Chan KS, Hung IF, Poon LL, Law Kl, Tang BS, Hon TY, Chan CS, Chan KH, Ng JS, Zheng BJ, Ng WL, Lai RW, Guan Y, Yuen KY, HKU/UCH SARS Study Group: Clinical progression and viral load in a community outbreak of coronavirus-associated SARS pneumonia: a prospective study. Lancet 2003, 361:1767-1772.

47. Gillim-Ross L, Taylor J, Scholl DR, Ridenour J, Masters PS, Wentworth DE: Discovery of novel human and animal cells infected by the severe acute respiratory syndrome coronavirus by replication-specific multiplex reverse transcription-PCR. J Clin Microbiol 2004, 42:3196-3206.

48. Poon LL, Chan KH, Wong OK, Cheung TK, Ng I, Zheng B, Seto WH, Yuen KY, Guan Y, Peiris JS: Detection of SARS coronavirus in patients with severe acute respiratory syndrome by conventional and real-time quantitative reverse transcription-PCR assays. Clin Chem 2004, 50:67-72.

doi:10.1186/1743-422X-11-82

Cite this article as: Yip et al: Antibody-dependent infection of human macrophages by severe acute respiratory syndrome coronavirus. Virology Journal 2014 11:82. 